\title{
PERAN KADER GENJEK PROMOSI KESEHATAN UNTUK MENCEGAH RESISTENSI MIKROBA
}

\author{
Lentar Aditya Djinu ${ }^{1}$, Ni Putu Aprilia Eka Susanti², I Putu Wily Anggara Wijaya ${ }^{3}$, Putu Hary \\ Chandrakrisna ${ }^{4}$, I Putu Okta Diwian Jaya Putra ${ }^{5}$
}

\begin{abstract}
Abstrak
Menurut catatan statistik dari Badan Pusat Statistik (2018), pada tahun 2002 hingga tahun 2014 di Bali terjadi peningkatan jumlah penduduk yang melakukan pengobatan sendiri yaitu dari $71,71 \%$ menjadi 79,80\%. Peningkatan tersebut merupakan peningkatan angka penduduk yang berobat sendiri dengan menggunakan obat modern. Peningkatan tersebut menunjukkan masyarakat Bali yang dalam hal ini mulai meremehkan kejadian penyakit. Salah satu budaya yang ditanamkan oleh orang tua di Bali pada anaknya adalah budaya untuk menghormati tradisi nenek moyang yang dilakukan secara turun-temurun. Pola pikir yang mudah dapat menyebabkan penggunaan obatobatan turun-temurun diwariskan kepada anak dan cucunya hingga akhirnya penggunaan obatobatan modern pada masa sekarang pun ikut diwariskan menggunakan pola pikir tersebut. Pada masa ini peranan anak dalam memengaruhi orang tua sangat terlihat. Pengaruh untuk berobat menggunakan kaidah Usada Bali perlu dilaksanakan oleh anak. Orang tua akan mulai memiliki pemahaman yang lebih tinggi tentang Usada Bali, sehingga anak dapat mempengaruhi Orang tua. Kesenian tradisional Genjek di Bali masih sangat erat digemari masyarakat Bali pada umumnya sudah menjadi ciri khas daerah tersebut. Maka GENOMS atau Genjek Promosi Kesehatan merupakan program pertunjukan oleh komunitas yang beranggotakan siswa SMA/sederajat yang memiliki kemampuan seni untuk mengenalkan Usada Bali kepada masyarakat melalui kesenian Bali berupa lagu Bali dan budaya magenjekan.
\end{abstract}

Kata kunci : Obat Modern, Usada Bali, Genjek

\begin{abstract}
According to statistical records from the Central Statistics Agency (2018), in 2002 to 2014 in Bali an increase in the number of residents doing self-medication was from $71.71 \%$ to $79.80 \%$. The increase is an increase in the number of residents who seek treatment themselves using modern medicine. This increase shows that the Balinese in this case began to underestimate the incidence of the disease. One culture that is instilled by parents in Bali in their children is a culture to honor ancestral traditions carried on for generations. The mindset that can easily lead to the use of drugs for generations passed down to children and grandchildren until finally the use of modern medicines today is also inherited using that mindset. At this time the role of children in influencing parents is very visible. The influence to seek treatment using the Usada Bali rules needs to be carried out by the child. Parents will begin to have a higher understanding of Usada Bali, so that children can influence parents. The traditional art of Genjek in Bali is still very closely favored by the Balinese people in general, which has become a characteristic of the area. So GENOMS or Genjek Health Promotion is a performance program by a community of high school / equivalent students who have the artistic ability to introduce Usada Bali to the public through Balinese art in the form of Balinese songs and magenjekan culture.
\end{abstract}

Keywords: Modern Medicine, Usada Bali, Genjek

\footnotetext{
I Fakultas Kedokteran Universitas Udayana, lentaradityadjinu@gmail.com

${ }^{2}$ Fakultas Kedokteran Universitas Udayana,aprlsusanti06@gmail.com

${ }^{3}$ Fakultas Kedokteran Universitas Udayana,willywijaya57@gmail.com

${ }^{4}$ Fakultas Kedokteran Universitas Udayana, harychandrakrisna@gmail.com

${ }^{5}$ Fakultas Kedokteran Universitas Udayana, oktadiwianjaya8@gmail.com
} 


\section{PENDAHULUAN}

Pada awalnya resistensi hanya ditemukan di tingkat rumah sakit, namun akhirnya juga ditemukan di lingkungan masyarakat, khususnya Streptococcus pneumoniae (SP), Staphylococcus aureus, dan Escherichia coli. (Peraturan Menteri Kesehatan Republik Indonesia Nomor 2406/MENKES/PER/XII/2011). Angka prevalensi dari penyakit infeksi masih masuk dalam 10 penyakit terbesar yang terdata oleh puskesmas di Provinsi Bali dibandingkan dengan penyakit tidak menular menurut data dari Dinkes Provinsi Bali tahun 2014. Hal ini dapat berarti telah terjadi perubahan pola infeksi dari organisme patogen, yang dapat disebabkan oleh penggunaan antibiotika dengan cara yang tidak rasional. Intensitas penggunaan antibiotik yang relatif tinggi dapat menimbulkan berbagai permasalahan dan merupakan ancaman global bagi kesehatan, terutama resistensi bakteri terhadap antibiotik.

Hal ini diperparah dengan masih adanya beberapa masyarakat Bali yang memegang erat tradisi dan budaya yang melekat pada setiap individunya dengan kental. Salah satu budaya yang ditanamkan oleh orang tua di Bali pada anaknya adalah budaya untuk menghormati tradisi nenek moyang yang dilakukan secara turun-temurun. Hal ini terus terjadi hingga salah satu keturunan tidak memahami tradisi tersebut, dan orang tua pun sama adanya. Mindset mudah memengaruhi itulah yang akan menyebabkan penggunaan obat-obatan turun-temurun diwariskan kepada anak dan cucunya hingga akhirnya penggunaan obatobatan modern pada masa sekarang pun ikut diwariskan menggunakan mindset tersebut.

SMA merupakan masa pendewasaan akhir bagi anak-anak, dimana pada masa ini peranan anak dalam memengaruhi orang tua sangat terlihat. Pengaruh untuk berobat menggunakan kaidah Usada Bali perlu dilaksanakan oleh anak. Orang dewasa akan merasa malu ketika orang yang lebih muda darinya justru memiliki pemahaman yang lebih tinggi tentang Usada Bali, sehingga mereka akan tergerak untuk ikut mempelajari Usada Bali bahkan mengikuti apa yang dianjurkan anaknya.

Kesenian tradisional di Bali masih sangat erat digemari masyarakat Bali pada umumnya sehingga sudah menjadi ciri khas daerah tersebut. Seperti halnya Genjek kini mulai dilestarikan dengan menggunakan lagu-lagu serta musik sehingga cocok untuk menyampaikan informasi ke masyarakat. Selain itu, kesenian genjek belakangan ini juga semakin digemari, dilihat dengan banyaknya lagu-lagu yang menggabungkan unsur pop dan genjek di kalangan anak muda. Maka GENOMS atau Genjek Promosi Kesehatan merupakan sebuah program pertunjukan oleh komunitas yang beranggotakan siswa SMA/sederajat yang memiliki kemampuan seni untuk mengenalkan Usada Bali kepada masyarakat melalui kesenian Bali berupa lagu-lagu Bali dan budaya magenjekan. GENOMS akan dipertunjukkan di Banjar Buaji Sari Keunggulan dari program ini antara lain; menjadi sarana pengembangan budaya Bali dalam bentuk nyanyian tradisional yang dapat memberi pengetahuan tentang Usada Bali bagi masyarakat dengan cara yang menarik, meningkatkan pengetahuan masyarakat kota yang kurang sadar mengenai Usada Bali, serta dapat menjadi media pengembangan soft skill bagi siswa-siswi SMA yang ikut terlibat di dalamnya. 
Tujuan program GENOMS adalah untuk meningkatkan pengetahuan dan wawasan masyarakat tentang bahaya pengobatan sendiri dengan antimikroba atau antibiotik secara berlebiha. Program ini diharapkan dapat berlanjut dengan terbentuknya ekstrakulikuler yang sebagai wadah edukasi siswa SMA Dwijendra untuk menyebar luaskan informasi kesehatan melalui kesenian di kalangan masyarakat, Program GENOMS yang berperan sebagai media promosi kesehatan melalui seni music tradisional genjek kontemporer yang berguna untuk menarik perhatian masyarakat lewat seni dan menyisipkan informasi kesehatan yang dimana masyarakat akan lebih mudah memahami music yang pada liriknya sudah disisipkan informasi kesehatan pengobatan herbal untuk mengurangi penggunaan antibiotic atau pengbatan sendiri dan melalui hal tersebut masyarakat dapat menyebar luaskan melalui satu orang ke orang lain khususnya di masyarakat luas. Dalam jangka panjang SMA Dwijendra dapat dijadikan sebagai contoh implementasi program "GENOMS" yaitu Genjek Promosi Kesehatan untuk mencegah resistensi mikroba melalui Kader dari SMA Dwijendra yaitu agar nantinya dapat diterapkan di sekolah lainnya di Denpasar khususnya dan di Bali pada umumnya.

\section{TINJAUAN PUSTAKA}

Peran vital dari antibiotik dalam mengatasi penyakit infeksi telah lama diketahui yaitu sejak diketemukannya spenisilin pada era 1920an hingga abad ke 20 sekarang. Banyaknya jenis antibiotik yang beredar membuat para klinisi semakin mudah untuk menangani penyakit infeksi. Hal ini pun memberi dampak yang kurang lebih sama pada masyarakat, dimana masyarakat dapat dengan mudah mengatasi penyakit infeksi bakteri hanya dengan mengkonsumsi antibiotik (Brooks dkk, 1998).

Pada rentang tahun 1986-2001, terjadi suatu pergeseran angka kematian akibat penyakit di Indonesia, yaitu penyebab utama kematian di Indonesia bukan lagi akibat infeksi. Hal ini menunjukkan bahwa penggunaan antibiotik di Indonesia sejak lama sudah membawa dampak yang positif untuk menurunkan angka kematian akibat infeksi di Indonesia (Handajani dkk, 2009).

Menurut catatan statistik dari Badan Pusat Statistik (2018), pada tahun 2002 hingga tahun 2014 di Bali terjadi peningkatan jumlah penduduk yang melakukan pengobatan sendiri yaitu dari $71,71 \%$ menjadi $79,80 \%$. Peningkatan tersebut merupakan peningkatan angka penduduk yang berobat sendiri dengan menggunakan obat modern. Peningkatan tersebut menunjukkan masyarakat Bali yang dalam hal ini mulai meremehkan kejadian penyakit.

\section{METODE}

\subsection{Teknik Penyuluhan}

Penyuluhan dilakukan oleh kader yang terdiri dari 21 siswa SMA Dwijendra Denpasar. Sebelum melaksanakan pementasan GENOMS, para kader terlebih dahulu melaksanakan pelatihan selama kurang lebih 2 minggu. Disini, kami melakukan penggabungan kalimatkalimat promkes yang telah dijadikan syair lagu dengan musik genjek sehingga menghasilkan koreografi yang menarik. Selanjutnya, diceritakan seorang pemeran yang menunjukkan keadaan tidak sehat dan pemeran lainnya membalas dengan sautan syair promkes yang telah dibuat, kemudian timbul kesinambungan antara 2 posisi pemeran. Sehingga gambaran konsep program GENOMS tersebut dapat berupa seperti berikut: 
1. Penabuh gamelan masuk, memainkan instrumen pembuka disertai masuknya para penari/pemeran genjek. Gamelan dimulai, terdapat drama syair antara pemeran yang mengalami sakit dan pemeran lain yang membalas syair dengan ajakan dan kalimatkalimat promosi kesehatan, yaitu tentang bahaya penyalahgunaan antibiotika dan pengenalan olahan tanaman herbal;

2. Pemeran "tokoh masyarakat" datang, kemudian menjelaskan himbauan penanaman TOGA kepada pemeran lain sekaligus kepada audiens.

3. Pemeran asisten rumah tangga yang kurang paham bahasa Bali datang, meminta agar syair-syair tadi dijelaskan dengan bahasa Indonesia. Hal ini berrtujuan agar materi yang disampaikan dapat dimengerti oleh seluruh masyarakat.

4. Dilanjutkan dengan pengulangan syair dengan musik yang lebih ceria dan membangkitkan semangat, dengan harapan agar dapat diingat lebih baik oleh warga atau bisa diikuti.

5. Pemeran "penyuluh kesehatan" dipanggil, kemudian menjelaskan bahaya resistensi antimikroba serta ajakan untuk menggunakan obat hasil olahan tanaman obat keluarga secara lebih detail.

6. Di akhir cerita, pemeran "tokoh masyarakat" bertanya kepada pemeran lain dan penonton, apakah mereka sudah paham terkait materi yang diberikan.

7. Drama diakhiri dengan persembahan tari dan gamelan penutup.

8. Salah satu anggota tim pelaksana bertanya kembali kepada penonton terkait materi yang diberikan, sekaligus memberikan hadiah hiburan bagi warga yang dapat menjawab pertanyaan yang diberikan. Hal ini dimaksudkan untuk mengetahui pemahaman masyarakat terkait materi setelah menyaksikan pementasan GENOMS, sekaligus memberikan apresiasi kepada warga yang telah menyimak dengan antusias.

\subsection{Pelatihan}

Siswa SMA Dwijendra Denpasar yang terpilih menjadi kader dilatih terlebih dahulu sebelum melaksanakan pementasan GENOMS. Pelatihan dilakukan sebanyak sembilan kali. Kegiatan dilakukan di tiga tempat berbeda, yaitu di SMA Dwijendra, di Gedung Timur Fakultas Kedokteran Universitas Udayana, dan di rumah salah satu kader. Ketiga tempat tersebut digunakan secara bergantian, menyesuaikan dengan situasi dan kondisi pada saat menjelang latihan. Pelatihan yang dilakukan antara lain pelatihan nada instrumen musik melodis yaitu seruling bambu, rindik, dan gitar; penyelarasan nada dasar vokal dan instrumen; penentuan gerak koreografi, serta pelatihan dialog antar pemeran dan ekspresi wajah.

Lirik yang digunakan dalam pelatihan Genjek Promosi Kesehatan mengandung ajakan pemanfaatan bahan kunyit, daun pegagan, tumbuhan putri malu dan daun sembung untuk bahan ramuan herbal guna mencegah resistensi mikroba akibat penggunaan antibiotik yang tidak wajar. Berdasarkan buku Tanaman Berkhasiat Obat di Indonesia yang ditulis Wijayakusuma (1996), daun pegagan merupakan bahan pembuatan ramuan herbal untuk mengobati sakit tenggorokan, yang diakibatkan oleh peradangan. Dalam pengolahannya, daun pegagan ditumbuk bersama kunyit dengan tambahan sedikit air dan madu sebagai penambah rasa manis. Menurut Suwidja (1991) kunyit mengandung zat antibiotika alami, sehingga dapat digunakan untuk membunuh bakteri dan mempercepat penyembuhan penyakit akibat radang. Hampir semua bahan herbal yang kami angkat diolah dengan cara direbus, dan hasil rebusannya kemudian dikonsumsi sebagai ramuan herbal. Secara tidak langsung, kami 
menganjurkan alternatif lain dengan mengurangi penggunaan antibiotik dan menggantinya dengan solusi yang lebih aman untuk mengatasi masalah kesehatan.

\subsection{Pendampingan IPTEK}

Selain itu, keberlanjutan program juga sebagai pemenuhan permintaan masyarakat, yang diwakili Lurah setempat meminta agar bersedia mengisi kegiatan bila diadakan penyuluhan atau pemberian informasi kepada masyarakat di kemudian hari. Program GENOMS akan kami serahkan kepada salah satu guru SMA Dwijendra Denpasar sebagai koordinator, yang selanjutnya akan menjadi penanggung jawab program ini. Selanjutnya melakukan pendampingan dalam hal pelatihan, pengembangan dan koordinasi kader ketika sudah dibentuk ekstrakulikuler untuk memfasilitasi kegiatan kedepannya. Pemantauan juga akan dilakukan dengan melakukan kunjungan setiap 2 minggu sekali ke SMA Dwijendra guna mengetahui perkembangan kader dan menjembatani permintaan untuk tampil lagi dari pihak luar.

\subsection{Evaluasi Transfer IPTEK saat Pelatihan}

Evaluasi dilakukan dengan memantau perilaku dan pemahaman siswa mengenai materi yang diberikan, hal ini dilihat dengan bagaimana siswa (kader) menyampaikan kembali materi yang kami berikan kepada teman-temannya sesama kader yang belum paham dan kepada masyarakat saat pelaksanaan. Hasilnya yaitu kader mampu menyampaikan materi dengan bahasa mereka sendiri serta improvisasi ketika penampilan GENOMS. Indikator lainnya yaitu ditemukannya partisipasi pada kader berupa antusias yang tinggi dan ikut memberikan saran maupun masukan kepada tim pelaksana terkait pelaksanaan GENOMS.

\section{HASIL DAN PEMBAHASAN}

\subsection{Hasil}

Berdasarkan hasil analisis deskriptif dari kegiatan yang telah berlangsung respon yang diberikan masyarakat diterima secara positif. Secara tidak langsung membuka wawasan masyarakat terkait pengobatan alternative lain yaitu penggunaan obat herbal guna untuk mengurangi penggunanaan antibiotik. Serta peningkatan pengetahuan terhadap jenis-jenis tanaman herbal untuk pengobatan dengan gejala penyakit ringan yang dapat diatasi dengan baik secara alamiah. Masyarakat dengan mudah memahami maksud dari informasi kesehatan yang disampaikan melalui media promosi kesehatan secara tradisional penampilan genjek kontemporer dan menikmati iringan music yang dimana secara tidak langsung terekam dalam otak dan tanpa sadar mulai ikut menyanyikan lagu dari penampilan genjek. Sehingga otak dapat mengingat dengan jelas lirik dari lagu genjek kontemporer yang dimana lirik tersebut sudah tersampaikan mengenai informasi kesehatan pengobatan herbal yang tepat.

\subsection{Keberlanjutan Program}

Keberlanjutan program GENOMS dengan merekomendasikan kegiatan ke pihask sekolah SMA Dwijendra bahwa kader yang telah berperan memberikan edukasi melalui seni tradisional Genjek kontemporer dan memiliki siswa-siswi kemampuan bakat dan minat di bidang kesenian sehingga pantas untuk dilanjutkan menjadi ekstrakulikuler karena telah menunjukan pengaruh positif di lingkungan masyarakat dengan menarik perhatian melalui seni trasdisional genjek tersebut. 


\section{KESIMPULAN}

Memperhatikan kembali bahwa dapat disimpulkan sebagai berikut; 1) Metode yang digunakan untuk memberikan bentu preventif terhadap penggunaan antibiotic secara berlebih yaitu melalui media promosi kesehatan yaitu seni music tradisional genjek; 2) Genjek Promosi Kesehatan "GENOMS" untuk mecegah dan mengurangi penggunaan antibiotic di lingkungan masyarakat; 3) Program GENOMS membentuk Kader anak sekolah yaitu SMA Dwijendra dengan minat kesenian; 4) Metode pelatihan berlangsung selama 2 minggu sebanyak 9 kali pertemuan; 5) Secara analisis deskriptif program ini dapat menarik perhatian masyarakat untuk menyaksikan penampilan kesenian bali yang telah disisipkan informasi kesehatan sehinggan pesan yang diberikan tersampaikan ke masyarakat 6) Kader secara tidak langsung menambah pengetahuan terkait kesehatan masyarakat.

\section{UCAPAN TERIMA KASIH}

Ucapan terimakasih kami sampaikan kepada berbagai pihak yang telah membantu pelaksanaan Program GENOMS ini yakni Direktorat Jenderal Pembelajaran dan Kemahasiswaan Kementerian Riset, Teknologi, dan Pendidikan Tinggi atas bantuan dana kegiatan; Universitas Udayana; serta Dr. drh. I Made Subrata, M.Erg atas bimbingannya sehingga program GENOMS ini dapat terlaksana dengan baik. 


\section{DAFTAR PUSTAKA}

Brooks, GF, Butel JS, Morse SA. 1998. Jawetz, Melnick, \& Adelberg's Medical Microbiology, 21st ed, Prentice Hall International Inc, , 145 - 176.

Depkes. 2014. PROFIL KESEHATAN PROVINSI BALI TAHUN 2013. Url: http://www.depkes.go.id/resources/download/profil/PROFIL_KES_PROVINSI_2013/1 7_Prov_Bali_2013.pdf

Hutapea, J. R. 2000. Inventarisasi Tanaman Obat Indonesia (I). Jakarta. Balitbangkes Depkes RI.

KEMENKES. 2011a. PEDOMAN PELAYANAN KEFARMASIAN UNTUK TERAPI ANTIBIOTIK. https://www.researchgate.net/profile/Fauna_Herawati/publication/303523653_Pedoman _Pelayanan_Kefarmasian_untuk_Terapi_Antibiotik/links/5746c02d08ae298602f9fc5b/ Pedoman-Pelayanan-Kefarmasian-untuk-Terapi-Antibiotik

KEMENKES. 2011b. PEDOMAN UMUM PENGGUNAAN ANTIBIOTIK. Url: http://jdih.pom.go.id/showpdf.php?u=cTcp0eStSVTlmXC7Av\%2BxK5RLEij8it\%2Fhu $\% 2$ FnLTo3HCOs\%3D

Suwidja, K. 1991. Berbagai Cara Pengobatan Menurut Lontar Usada Pengobatan Tradisional Bali. Indra Jaya: Singaraja. 